I BIENAL LATINOAMERICANA DIDH

\title{
Derechos indígenas a los recursos naturales, al agua y al medio ambiente en el derecho internacional
}

\author{
Indigenous rights to natural resources, water \\ and the environment in international law
}

\author{
Nancy Yáñez Fuenzalida \\ Universidad de Chile
}

\begin{abstract}
RESUMEN Este artículo analiza los desarrollos normativos y estándares generados en el derecho internacional de los derechos humanos respecto del entorno y los derechos indígenas sobre sus territorios y recursos naturales. A partir del análisis del Convenio 169 y de la evolución de los estándares en el seno del Sistema Interamericano de Derechos Humanos, se verifica que el derecho internacional reconoce el derecho de propiedad de los pueblos indígenas sobre sus territorios ancestrales y, como consecuencia, el derecho sobre los recursos naturales que han sido tradicionalmente usados para su supervivencia, desarrollo y prosecución de su sistema de vida y costumbre. Sin embargo, a partir de jurisprudencia reciente del Sistema, se observa el desarrollo de estándares específicos de derechos ambientales a pueblos indígenas, con el derecho al medio ambiente reconocido como un derecho autónomo que implica la protección de la naturaleza en sí misma y los elementos que la componen, independiente de si hay afectación directa a las personas como consecuencia del daño ambiental. También es relevante la relación que se observa en el derecho internacional entre identidad cultural y medio ambiente, para asegurar las formas de vida tradicionales de los pueblos indígenas, su soberanía alimentaria y su sustentabilidad hídrica.
\end{abstract}

PALABRAS CLAVE Pueblos indígenas, territorio, recursos naturales, medio ambiente, derecho de la naturaleza, identidad cultural, soberanía alimentaria, derecho al agua y la sustentabilidad hídrica.

ABSTRACT This article analyses the normative developments and standards generated in international human rights law with respect to the environment and the rights of indigenous peoples over their territories and natural resources. Following the analysis of Convention 169 and the evolution of standards within the Inter-American System of Human Rights (ISHR), it is verified that international law recognizes the right of indigenous peoples to property over their ancestral territories and, as a consequence, the right to natural resources that have been traditionally used for their survival, devel- 


\begin{abstract}
opment and the continuation of their system of life and custom. However, recent ISHR jurisprudence shows the development of specific standards of environmental rights for indigenous peoples, recognizing the right to the environment as an autonomous right that implies the protection of nature itself and the elements that comprise it, regardless of whether there is a direct impact on people as a result of environmental damage. Also relevant is the relationship observed in international law between cultural identity and the environment, in order to ensure the traditional ways of life of indigenous peoples, their food sovereignty, and water sustainability.
\end{abstract}

KEYWORDS Indigenous peoples, territory, natural resources, environment, right to nature, cultural identity, food sovereignty, right to water and water sustainability.

\title{
Introducción
}

En el presente artículo analizaremos los desarrollos normativos y estándares generados en el derecho internacional de los derechos humanos respecto del entorno y los derechos indígenas sobre sus territorios y recursos naturales.

En primer lugar, hacemos un análisis de los instrumentos de derecho internacional que regulan los derechos indígenas al territorio, la tierra, los recursos naturales y el medio ambiente. A continuación, recogemos los estándares generados en el Sistema Interamericano de Derechos Humanos en base al derecho de propiedad indígena respecto a la tierra y los recursos naturales, y la evolución que ha tenido el reconocimiento del derecho al medio ambiente de los pueblos indígenas. Finalmente, incorporamos un acápite de conclusiones que evidencia los importantes avances en el reconocimiento de estos derechos en el contexto del derecho internacional de los derechos humanos y, en particular, en el Sistema Interamericano de Derechos Humanos, relevando la evolución del derecho al medio ambiente como derecho autónomo y, asimismo, la interrelación del derecho con la integridad cultural indígena, el derecho a la alimentación adecuada y el derecho al agua.

\section{Marco normativo de derecho internacional sobre derechos indígenas al territorio, la tierra, los recursos naturales y el medio ambiente}

El derecho internacional reconoce el derecho de propiedad de los pueblos indígenas sobre sus territorios ancestrales y, como consecuencia, el derecho sobre los recursos naturales existentes en esos territorios, que han sido tradicionalmente usados para su supervivencia, desarrollo y prosecución de su sistema de vida y costumbre. ${ }^{1}$ Así se

1. «Informe de derechos de los pueblos indígenas y tribales sobre sus tierras ancestrales y recursos naturales», Comisión Interamericana de Derechos Humanos, Normas y jurisprudencia del Sistema Interamericano de Derechos Humanos, OEA/Ser.L/V/II., Doc. 56/o9, 30 de diciembre de 2009. 
expresa en el Convenio 169 de la Organización Internacional del Trabajo (OIT) —en el que se reconocen derechos específicos en este ámbito a los pueblos indígenas-, la Declaración Universal de Derechos Indígenas y otros instrumentos de derechos humanos de aplicación general, como el Pacto de Derechos Civiles y Políticos (PDCP), el Pacto de Derechos Económicos Sociales y Culturales (PDESC), y la Convención Americana de Derechos Humanos, sobre la base de los cuales se han amparado los derechos territoriales indígenas por medio de la interpretación evolutiva que de ellos han hecho los tribunales internacionales y los órganos encargados de su aplicación. ${ }^{2}$

El Convenio 169 reconoce el derecho al medio ambiente, la subsistencia, el desarrollo y la protección de los recursos naturales. El Convenio 169, artículos 4.1 y 7.4, impone a los Estados la obligación de adoptar medidas para proteger el medio ambiente indígena. En este plano, es obligación de los gobiernos velar por que se efectúen estudios, en cooperación con los pueblos indígenas, que permitan determinar los impactos sociales, espirituales, culturales y sobre el medio ambiente que las actividades de desarrollo puedan generar en estos pueblos (artículo 7.3). Se reconoce los derechos de subsistencia de los pueblos indígenas, y en particular se dispone que la artesanía, las industrias rurales y comunitarias y las actividades tradicionales y relacionadas con la economía de subsistencia de los pueblos interesados, como la caza, la pesca y la recolección, entre otras, sean reconocidas como factores importantes para el mantenimiento de la cultura, su autosuficiencia y desarrollo económicos, por lo que es obligación de los gobiernos velar por que se fortalezcan y fomenten dichas actividades (artículo 23). El derecho al desarrollo de los pueblos indígenas, acorde con el artículo 7.1 del Convenio 169, se estructura en torno al derecho a la libre determinación salvaguardando la facultad de estos pueblos a establecer sus prioridades en materia de desarrollo, cuestión de extrema relevancia cuando este modelo colisiona con el que pretende imponer el Estado, por cuenta propia o de particulares, y en el que se disputa el control sobre los recursos naturales en los territorios indígenas. El artículo 15.1 reconoce los derechos de los pueblos indígenas a los recursos naturales existentes en sus tierras e impone al Estado la obligación de proteger especialmente estos derechos y garantizar la participación indígena en la utilización, administración y conservación de dichos recursos. Se dispone, sin embargo, que si la propiedad de estos recursos pertenece al Estado conforme a la legislación doméstica, se deben adoptar medidas para proteger y preservar los territorios de los pueblos indígenas, como consulta previa,

2. La Corte IDH, en la sentencia del caso Comunidad Mayagna (Sumo) Awas Tingni con Nicaragua, fondo, reparaciones y costas, serie C núm. 79, 31 de agosto de 2001. párr. 148, estableció esta tendencia jurisprudencial que implica una interpretación evolutiva de la Convención Americana de Derechos Humanos $(\mathrm{CADH})$ a la luz de otros instrumentos de derechos humanos, basado en el artículo 29 letra b) de la $\mathrm{CADH}$, que prohíbe una interpretación restrictiva de los derechos. 
libre e informada; participación en los beneficios de la explotación y la compensación por los daños (artículo 15.2) (Yáñez, 2014).

Estos derechos también han sido reconocidos en el artículo 8 letra j) de la Convención sobre Biodiversidad y en la Agenda 21, capítulo 26, ambos instrumentos adoptados en el marco de la Conferencia Mundial sobre el Medio Ambiente y el Desarrollo, celebrada en Río de Janeiro en $1992{ }^{3}$

El artículo 8, inciso j, impone a los Estados una obligación específica de respetar, preservar y mantener los conocimientos, las innovaciones y las prácticas de las comunidades indígenas y locales que entrañen estilos tradicionales de vida pertinentes para la conservación y la utilización sostenible de la diversidad biológica con participación (Yáñez, 2014). La Agenda 21, por su parte, «sobreentiende que el término "tierras" abarca el medio ambiente de las zonas que esas poblaciones ocupan tradicionalmente» (párrafo 26.1).

\section{Estándares Interamericanos respecto al derecho de propiedad indígena a las tierras, a los recursos naturales y el derecho al medio ambiente}

La Corte Interamericana de Derechos Humanos ha reconocido la propiedad comunal indígena a las tierras y recursos naturales, aplicando el artículo 21 de la Convención Americana de Derechos Humanos. ${ }^{4}$ Este reconocimiento se ha dado en el

3. Documentos generados en el seno de Naciones Unidas o en el marco del decenio Internacional para la Acción «El agua fuente de vida, 2005-2015», plan de aplicación de las decisiones de la Cumbre Mundial sobre Desarrollo Sostenible de Johannesburgo, 26 de agosto al 4 de septiembre de 2002; Declaración Ministerial del Foro Mundial del Agua de Kioto, 22 y 23 de marzo de 2003, «Mensaje del Lago Biwa y de la Cuenca del Río Yodo»; Declaración de la conferencia organizada por el Programa de Medio Ambiente de Naciones Unidas en Nairobi, 17 de enero de 2006, Worker's initiative for a Lasting Legacy (WILL, por sus siglas en inglés), 2006.

4. La Corte IDH, en sentencia del caso Comunidad Mayagna (Sumo) Awas Tingni con Nicaragua, fondo, reparaciones y costas, serie C núm. 79, 31 de agosto de 2001. párr. 148, reconoció el valor de la propiedad comunal de los pueblos indígenas a la luz del artículo 21 de la Convención Americana de Derechos Humanos. Asimismo, reconoció la validez de la posesión de la tierra basada en la costumbre indígena, aun a falta de título, como fundamento de su propiedad sobre ellas; y, finalmente, estableció la necesidad de que la estrecha relación que los indígenas tienen con sus tierras sea reconocida y comprendida como la base fundamental de sus culturas, su vida espiritual, su integridad y su supervivencia económica. Esta jurisprudencia se ha ratificado en una multiplicidad de casos: sentencia del caso Comunidad Indígena Yakye Axa con Paraguay, fondo, reparaciones y costas, serie C núm. 125, 17 de junio de 2005, párr. 137; sentencia del caso Comunidad Indígena Sawhoyamaxa con Paraguay, fondo, reparaciones y costas, serie C núm. 146, 29 de marzo de 2006, párrs. 118, 121; sentencia del caso Pueblo Saramaka con Surinam, excepciones preliminares, fondo, reparaciones y costas, serie C núm. 172, 28 de noviembre de 2007, párr. 120; sentencia del caso Comunidad Indígena Xákmok Kásek con Paraguay, fondo, reparaciones y costas, serie C núm. 214, 24 de agosto de 2010, párr. 85; sentencia del caso Pueblo Indígena Kichwa de Sarayaku con Ecuador, fondo y reparaciones, serie C núm. 245, 27 de junio de 2012, párr. 145. 
marco de las disputas generadas por el control de los recursos naturales, bosques, agua y minerales, entre otros, existentes en los territorios donde habitan los pueblos indígenas y tribales. Esta disputa se acentúa debido a la colisión de derechos entre el reconocimiento de la propiedad indígena y los derechos de los Estados, a quienes las normas constitucionales o legales en el derecho doméstico les asignan la propiedad de los recursos naturales del subsuelo y de los recursos hídricos. ${ }^{5}$

El Sistema Interamericano de Derechos Humanos se hace cargo de esta situación asumiendo, en concordancia con lo establecido en el artículo 15.2 del Convenio 169, que si bien es legítimo que los Estados se reserven formalmente la propiedad de los recursos del subsuelo y del agua, esto no implica desconocer el derecho de los pueblos indígenas o tribales a ser respetados en relación con el proceso de exploración y extracción de recursos del subsuelo o recursos hídricos, ni tampoco implica que las autoridades estatales tengan plena libertad para disponer de dichos recursos a su discreción (Yáñez, 2014). Por el contrario, se sostiene, la jurisprudencia interamericana ha identificado derechos de los pueblos indígenas y tribales que los Estados deben respetar y proteger cuando pretendan extraer los recursos del subsuelo o explotar los recursos hídricos, y que incluyen el derecho a un medio ambiente seguro y sano, el derecho a la consulta previa y, en ciertos casos, al consentimiento informado, el derecho a la participación en los beneficios del proyecto, y el derecho de acceso a la justicia y a la reparación. ${ }^{6}$

Los derechos de propiedad de los pueblos indígenas y tribales se extienden a los recursos naturales presentes en sus territorios, como una consecuencia necesaria del derecho de propiedad territorial 7 y en clara correspondencia con la noción de territorialidad indígena acuñada por el Convenio 169 de la OIT y la Declaración Universal sobre los Derechos de los Pueblos Indígenas. ${ }^{8}$ La Corte IDH ha determinado que la protección de la propiedad indígena sobre los recursos naturales es necesaria para mantener sus formas de vida y costumbres. Por ello, la protección se extiende también a los derechos culturales e impone la obligación de garantizar actividades indígenas relacionadas con los recursos naturales como la pesca, la caza o la recolección. ${ }^{9}$

5. «Derechos de los pueblos indígenas y tribales sobre sus tierras ancestrales y recursos naturales: Normas y jurisprudencia del Sistema Interamericano de Derechos Humanos», Comisión Interamericana de Derechos Humanos, OEA/Ser.L/V/II., Doc. 56/o9, 30 diciembre 2009, párr. 179 y 180.

6. «Derechos de los pueblos...», párr. 180.

7. Sentencia del caso Comunidad Indígena Yakye Axa con Paraguay, párrs. 124, 137; sentencia del caso Comunidad Indígena Sawhoyamaxa con Paraguay, párrs. 118, 121; sentencia del caso Pueblo Saramaka con Surinam, párr. 122, subtítulo D. Corte IDH Caso Pueblo Indígena Kichwa de Sarayaku con Ecuador, párr. 146.

8. «Derechos de los pueblos...», párr. 182.

9. «Derechos de los pueblos...», párr. 184; sentencia del caso Comunidad Indígena Yakye Axa con Paraguay, párr. 154; sentencia del caso Xkamok Kasek con Paraguay, Corte Interamericana de Derechos 
En 2005 (caso Comunidad Indígena Yakye Axa con Paraguay), la Corte IDH estableció que los derechos territoriales indígenas abarcan un concepto más amplio que la propiedad, relacionado con el derecho colectivo a la supervivencia como pueblo organizado, con el control de su hábitat como una condición necesaria para la reproducción de su cultura, para su propio desarrollo y para llevar a cabo sus planes de vida. ${ }^{10} \mathrm{El}$ fallo concluye que los peticionarios, miembros de la comunidad yakye axa, viven en condiciones de miseria extrema como consecuencia de la falta de tierra y acceso a recursos naturales, y que por ello ven imposibilitado el acceso a una vivienda adecuada dotada de los servicios básicos mínimos, así como a agua limpia y servicios sanitarios, lo que constituye una infracción por parte del Estado de Paraguay a la luz de los derechos garantizados por la Convención. ${ }^{11}$

También se ha pronunciado el Sistema Interamericano de Derechos Humanos sobre el derecho a la integridad ambiental (Yáñez, 2014). A este respecto, la CIDH plantea que si bien la protección del medio ambiente no está reconocida en forma expresa en la Declaración Americana de los Derechos y Deberes del Hombre ni tampoco en la Convención Americana de Derechos Humanos, varios derechos de rango fundamental como el derecho a la vida, a la seguridad y la integridad física y a la salud requieren como precondición necesaria para su ejercicio una calidad medioambiental mínima, por lo que la contaminación y degradación del medio ambiente amenaza estos derechos. ${ }^{12}$

En un fallo reciente, la Corte Interamericana de Derechos se pronuncia sobre los derechos a un medio ambiente sano, a la alimentación adecuada, al agua y a parti-

Humanos, fondo, reparaciones y costas, serie C núm. 214, 24 de agosto de 2010, párr. 113; sentencia del caso Pueblo Indígena Kichwa de Sarayaku con Ecuador, párr. 148.

10. Sentencia del caso Comunidad Indígena Yakye Axa con Paraguay, párr. 146. A esta misma conclusión arriba la Corte IDH en el caso Pueblo Indígena Kichwa de Sarayaku con Ecuador, párr. 147.

11. Sentencia del caso Comunidad Indígena Yakye Axa con Paraguay, párr. 164.

12. La CIDH se ha pronunciado sobre esta materia en una multiplicidad de informes sobre la situación de derechos humanos en los países partes del Sistema Interamericano. Véase «La situación de los derechos humanos en Cuba: Séptimo informe», OEA/Ser.L/V/II.61, Doc.29 rev. 1, 4 de octubre de 1983, en los párrs. 1, 2, 41, 60 y 61, se pronunció sobre la relación entre la protección del medio ambiente y el derecho a la salud, para el cual es necesaria la provisión de agua, servicios de higiene y saneamiento y de disposición de residuos; «Informe sobre la situación de los derechos humanos en Ecuador», OEA/ Ser.L/V/II.96, Doc.10 rev.1, 24 de abril de 1997; «Tercer informe sobre la situación de los derechos humanos en Colombia», OEA/Ser.L/V/II.102, Doc.9 rev.1, 26 de febrero de 1999; «Tercer informe sobre la situación de los derechos humanos en Paraguay», OEA/Ser./L/VII.11o, Doc.52, 9 de marzo de 2001; "Acceso a la justicia e inclusión social: El camino hacia el fortalecimiento de la democracia en Bolivia», OEA/Ser.L/V/II, Doc. 34, 28 de junio de 2007; «Democracia y derechos humanos en Venezuela», OEA/ Ser.L/V/II, Doc.54, 30 de diciembre de 2009. La Corte IDH se ha pronuncia sobre el derecho a la integridad ambiental en el caso Pueblo Saramaka con Surinam. 
cipar en la vida cultural, aplicando el artículo 26 de la Convención. ${ }^{13}$ Haciendo un análisis sistemático entre la Convención y la Carta de la Organización de los Estados Americanos, reconoce que el derecho al medio ambiente sano se entiende incluido en el artículo 26 de la Convención y que dimana de la obligación de los Estados de alcanzar el «desarrollo integral» de sus pueblos, ${ }^{14}$ según lo establecen los artículos 30, 31, 33 y 34 de la Carta de la OEA..$^{15}$

Precisando el alcance y contenido sustantivo del derecho al medio ambiente, el fallo se remite a su Opinión Consultiva OC-23/17, relevando que se trata de un derecho autónomo que protege los componentes del ambiente, como bosques, mares, ríos y otros. Protege la naturaleza y sus componentes, como intereses o bienes jurídicos en sí mismos, aun cuando no se tenga certeza o evidencia sobre el riesgo a las personas. Se trata de proteger la naturaleza y su utilidad respecto de todos los organismos vivos del planeta, no solo respecto de los seres humanos. La Corte IDH precisa que, no obstante que el derecho al medio ambiente es un derecho autónomo, es incuestionable que otros derechos humanos puedan ser vulnerados como consecuencia de daños ambientales y, de igual modo, deben ser salvaguardados (párrafo 203).

El Estado tiene, respecto de este derecho, la obligación de respeto y de garantía, de modo que prevenga vulneraciones de terceros. Se consigna que esta obligación de prevenir daños ambientales forma parte del derecho internacional consuetudinario. Se establece que los estándares exigibles al Estado para la aplicación del principio de prevención, frente a actividades potencialmente dañosa al medio ambiente, son: i) regular; ii) supervisar y fiscalizar; iii) requerir y aprobar estudios de impacto ambiental; iv) establecer planes de contingencia, y v) mitigar en casos de ocurrencia de daño ambiental (párrafo 208).

La debida diligencia supone hacerse cargo de la circunstancia que las problemáticas ambientales pueden afectar de modo diferenciado a pueblos, grupos y personas en condición de vulnerabilidad, como los pueblos indígenas, quienes dependen para su economía y supervivencia de la integridad de los recursos ambientales que configuran su hábitat (párrafo 209).

Sobre el contenido del derecho a la alimentación, la Corte IDH se sustenta en la Observación General 12 del Comité de Derechos Económicos, Sociales y Culturales (DESC), el que señaló que el «contenido básico» del derecho a la alimentación

13. Sentencia del caso Comunidades Indígenas Miembros de la Asociación Lhaka Honhat (Nuestra Tierra) con Argentina, Corte Interamericana de Derechos Humanos, excepciones preliminares, fondo, reparaciones y costas, Serie C núm. 400, 6 de febrero de 2020. párr. 201.

14. Nancy Yáñez, "Caso Lhaka Honhat: Los avances del Sistema Interamericano de Derechos Humanos», Debates Indígenas, 1 de mayo de 2020, disponible en https://bit.ly/2E8RCw8.

15. Sentencia del caso Comunidades Indígenas Miembros de la Asociación Lhaka Honhat (Nuestra Tierra) con Argentina, párr. 202. 
comprende «la disponibilidad de alimentos en cantidad y calidad suficientes para satisfacer las necesidades alimentarias de los individuos, sin sustancias nocivas, y aceptables para una cultura determinada», $y$ «la accesibilidad de esos alimentos en formas que sean sostenibles y que no dificulten el goce de otros derechos humanos» (párrafo 218).

El fallo releva los componentes culturales del derecho y su incidencia en la conceptualización de los estándares de adecuación y seguridad alimentaria, que son propios del derecho. ${ }^{16}$ En el mismo sentido, la Corte IDH se pronunció sobre el derecho al agua ${ }^{17}$ y fijó sus contenidos normativos según lo establecido por el Comité DESC en la Observación General 15. ${ }^{18}$

Lo más novedoso de esta jurisprudencia es el análisis sistemático que la Corte IDH hace de los derechos mencionados en este acápite y su interdependencia, ${ }^{19} \mathrm{di}$ mensionando la forma en que estos derechos (al agua, a la alimentación y a participar en la vida cultural) son particularmente vulnerables a las afectaciones ambientales. ${ }^{20}$ De la misma forma, cabe connotar la sentencia en cuanto integra al análisis la necesaria relación entre identidad cultural y desarrollo integral de los pueblos, comunidades y grupos sociales del continente, según el marco normativo que provee la Carta $\mathrm{OEA},{ }^{21}$ precisando que «el derecho protege los rasgos distintivos que caracterizan a un grupo social, sin que ello implique negar el carácter histórico, dinámico y evolutivo de la cultura», ${ }^{22}$ reconociendo la contribución de estos grupos en la definición de otra concepción de desarrollo. ${ }^{23}$

Los Pactos de Derechos Humanos, Pacto de Derechos Civiles y Políticos (PDCP) y Pacto de Derechos Económicos, Sociales y Culturales (PDESC), a los que alude la Corte IDH en su reciente sentencia, reconocen que el derecho de los pueblos sobre sus recursos naturales está ligado al ejercicio del derecho de libre determinación y que ello constituye la piedra angular para articular sus estrategias de desarrollo.

16. Sentencia del caso Comunidades Indígenas Miembros de la Asociación Lhaka Honhat (Nuestra Tierra) con Argentina, párrs. 220-221.

17. Sentencia del caso Comunidades Indígenas Miembros de la Asociación Lhaka Honhat (Nuestra Tierra) con Argentina, párrs. 226-230.

18. Comité DESC, Observación General 15, el derecho al agua (artículos 11 y 12 del Pacto Internacional de Derechos Económicos, Sociales y Culturales).

19. Véase epígrafe B.1.2, «Interdependencia entre los derechos a un ambiente sano, a la alimentación adecuada, al agua y a la identidad cultural y especificidades en relación con pueblos indígenas».

20. Yáñez, «Caso Lhaka Honhat».

21. Sentencia del caso Comunidades Indígenas Miembros de la Asociación Lhaka Honhat (Nuestra Tierra) con Argentina, párr. 231.

22. Sentencia del caso Comunidades Indígenas Miembros de la Asociación Lhaka Honhat (Nuestra Tierra) con Argentina, párr. 240.

23. Yáñez, «Caso Lhaka Honhat». 
En efecto, el artículo 1, inciso segundo del PDCP y el mismo precepto del PDESC reconocen el derecho a la libre determinación de todos los pueblos y lo vinculan al derecho sobre los recursos naturales, al señalar que,

para el logro de sus fines, todos los pueblos pueden disponer libremente de sus riquezas y recursos naturales, sin perjuicio de las obligaciones que derivan de la cooperación económica internacional basada en el principio de beneficio recíproco, así como del derecho internacional. En ningún caso podrá privarse a un pueblo de sus propios medios de subsistencia.

También se reconoce el derecho a la cultura en el artículo 27, que dispone:

En los Estados en que existan minorías étnicas, religiosas o lingüísticas, no se negará a las personas que pertenezcan a dichas minorías el derecho que les corresponda, en común con los demás miembros de su grupo a tener su propia vida cultural, a profesar y practicar su propia religión y a emplear su propio idioma.

Para interpretar los artículos 1 y 27 del PDCP, el Comité ha adoptado dos observaciones generales: Observación General 12 (1984), derecho de libre determinación (artículo 1); y la Observación General 23 (1994), derechos de las minorías (artículo 27). En la práctica, el Comité de Derechos Humanos se ha pronunciado sobre la protección de los recursos naturales indígenas para la preservación de su cultura aplicando el artículo 27 del PDCP, ya que el Comité se ha declarado incompetente para pronunciarse, bajo el mecanismo de quejas individuales que instaura el Protocolo Facultativo del PDCP, de violaciones al derecho de libre determinación. ${ }^{24}$ Sin embargo, ha relevado la importancia del derecho de libre determinación «como condición esencial para la eficaz garantía y observancia de los derechos humanos individuales y para la promoción y fortalecimiento de esos derechos». ${ }^{25}$

24. En el caso Jefe Bernard Ominayac y miembros de la agrupación del Lago Lubicón con Canadá (Com. 167/1984), Dictamen de 26/3/1990, párrs. 1, 2.1 y 2.3, se alegó la violación del derecho a la libre determinación y, en particular, el derecho de la comunidad indígena del lago Lubicón a disponer libremente de sus riquezas y recursos naturales y proveer al desarrollo económico, social y cultural. El Comité interpretó el protocolo facultativo en el sentido de que lo inhibe de conocer de presuntas violaciones al derecho a la libre determinación, razonando del siguiente modo: «El Comité reafirma que [...] el Pacto [...] reconoce y protege en los términos más enérgicos el derecho de un pueblo a la libre determinación y su derecho a disponer de sus recursos naturales, como condición esencial para la eficaz garantía y observancia de los derechos humanos individuales y para la promoción y fortalecimiento de esos derechos. No obstante, el Comité observa que el autor, como persona individual, no puede afirmar con arreglo al protocolo facultativo que es víctima de una violación del derecho a la libre determinación consagrado en el artículo 1 del Pacto, que trata de los derechos reconocidos a los pueblos como tales» (O’Donell, 2007: 860).

25. Comité de Derechos Humanos, Observación General 12, párr. 1. 
El Comité de Derechos Humanos, basado en el artículo 27 del PDCP, ha salvaguardado las actividades económicas de los pueblos indígenas vinculadas al uso y aprovechamiento de recursos naturales cuando hacen parte de la cultura. Ha determinado que ello constituye un límite a la libertad económica de los Estados, los que no pueden disponer de estos recursos naturales si ello amenaza la integridad cultural de los pueblos indígenas, mientras que deben garantizar además el derecho de participación de los pueblos interesados. ${ }^{26}$

La jurisprudencia generada en el Sistema Interamericano de Derechos Humanos ha establecido que en la medida de que los pueblos indígenas y tribales tienen derecho de propiedad sobre los recursos naturales presentes en sus territorios ancestrales, los Estados deben tomar medidas efectivas, de acuerdo con sus patrones tradicionales de uso y ocupación, para asegurar la plena garantía del derecho. ${ }^{27}$ En este contexto, se dispone expresamente que el reconocimiento del derecho propio indígena

26. La jurisprudencia más relevante en la materia está determinada por los siguientes casos: caso Iván Kitok con Suecia (Com. 197/1985), dictamen del 27 de julio de 1988, párr. 9.2; esta jurisprudencia es precursora en considerar la relación entre actividad económica del Estado y la cultura de una comunidad indígena, y proveer protección al amparo del artículo 27 del PDCP. Caso Jefe Berrnard Ominayac y miembros de la agrupación del Lago Lubicón con Canadá (Com. 167/1984), dictamen del 26 de marzo de 1990, párrs. 32.2, 33; en este caso se estableció que las actividades económicas que forman parte de la cultura y el modo particular de vida de una comunidad indígena deben ser salvaguardadas de amenazas. Se determinó que «los derechos protegidos por el artículo 27 incluyen los derechos de las personas, en comunidad con otros, para comprometerse en actividades económicas y sociales que son parte de la cultura de la comunidad a la cual pertenecen». El Comité reconoció que la subsistencia y actividades económicas tradicionales de los pueblos indígenas son parte integrante de su cultura, y que la interferencia con esas actividades, en ciertos casos, podía ser perjudicial para su integridad cultural y supervivencia. Caso Länman y otros con Finlandia (Com. 511/1992), dictamen del 26 de octubre de 1994; la libertad económica del Estado se mide por la referencia a las obligaciones que impone artículo 27 del PDCP. Caso Diergaardt y otros con Namibia, (Com. 760/1997), dictamen del 25 de julio de 200o, párrs. 2.1, 2.3, 3.1 y 10.6; especifica que el derecho de los miembros de una minoría a disfrutar de su cultura conforme al artículo 27 comprende la protección de un modo particular de vida relacionado con el uso de los recursos de tierras mediante actividades económicas, como caza y pesca, especialmente en el caso de pueblos indígenas, por lo que es insuficiente para la aplicación del precepto acreditar exclusivamente el uso comunitario de tierras para pastoreo. Caso Apirana Mahuika y otros con Nueva Zelandia (Com. 547/1993), dictamen del 16 de noviembre de 2000; las actividades económicas entran en el artículo 27 del PDCP, cuando son un elemento indispensable en la cultura de una comunidad, en este caso las actividades pesqueras, aun cuando no se trate de actividades de subsistencia. Caso Angela Poma Poma con Perú, dictamen del 24 de abril de 2009; se determinó que las actividades económicas de valor cultural demandan participación en el proceso que involucra la extracción de recursos; la participación debe ser efectiva y se requiere el consentimiento libre, previo e informado de los miembros de la comunidad; la falta de consulta, estudios de impacto ambiental y medidas para minimizar e imposibilidad de seguir con la actividad comprometen de manera sustantiva el modo de vida y la cultura, párrs. 7.4; 7.5; 7.6; y 7.7 (Henderson, 2011).

27. «Derechos de los pueblos...», párr. 185. 
por parte de las autoridades estatales y de los tribunales de justicia es una condición necesaria para que los pueblos indígenas puedan hacer valer sus derechos sobre los recursos naturales. ${ }^{28}$ Estos derechos no pueden ser extinguidos o alterados por el Estado sin que se salvaguarden las garantías del derecho de propiedad que concurren en caso de expropiación ${ }^{29} \mathrm{y}$, en todo caso, se respeten las garantías específicas de derechos indígenas, como son la consulta y, cuando corresponda, el consentimiento previo libre e informado. ${ }^{30}$

El Sistema Interamericano de Derechos Humanos, por medio de la jurisprudencia de la Corte IDH, ha establecido las siguientes obligaciones estatales en materia de derechos territoriales: i) deber de reconocer que la posesión de tradicional de las tierras indígenas por parte de los pueblos indígenas y tribales tiene efectos jurídicos homologables al título de dominio pleno que otorga el Estado e incluye el concepto de territorios; ii) deber de reconocer que dicha posesión tradicional otorga a los pueblos indígenas el derecho a exigir el reconocimiento oficial de la propiedad y su registro y el derecho a no ser trasladados; iii) deber de proceder a la demarcación, delimitación y titulación de las tierras indígenas; iv) deber de restituir, cuando corresponda, las tierras tradicionales a la comunidades, cuando por causas ajenas a su voluntad hayan salido de sus tierras tradicionales o perdido la posesión de las mismas y estas se encuentran en manos de terceros; v) deber de otorgar tierras alternativas de la misma extensión y calidad que las pérdidas, cuando en forma excepcional la restitución no fuera posible, las que deben acordadas libremente con las comunidades y sus legítimos representantes; vi) deber de indemnizar plenamente a las personas trasladadas y reubicadas como consecuencia de cualquier daño que hayan sufrido a causa del desplazamiento (Steiner y Fuchs, 2019: 632-634).

Tratándose de tierras indígenas no tituladas, la obligación internacional del Estado es demarcar y titular los territorios indígenas para proveer certeza jurídica sobre el dominio ancestral indígena. Antes de la demarcación y titulación de estos territorios - como ha consignado la Corte IDH— ${ }^{31}$ el Estado se debe abstener de cualquier tipo de actos que puedan afectar la integridad de los territorios indígenas. ${ }^{32}$

La Corte IDH ha reconocido el derecho del Estado a subordinar el uso y goce de los bienes de propiedad indígena sobre la tierra y recursos naturales a los intereses de la sociedad, exigiendo en dichas circunstancia las condiciones impuestas por el artículo 21 de la CADH para la expropiación, ${ }^{33}$ a saber: i) las restricciones a la pro-

\footnotetext{
28. «Derechos de los pueblos...», párr. 185.

29. "Derechos de los pueblos...", párrs. 229-231.

30. «Derechos de los pueblos...», párr. 186.

31. Sentencia del caso Pueblo Saramaka con Surinam, párr. 194.

32. Sentencia del caso Pueblo Saramaka con Surinam, párr. 196.

33. Sentencia del caso Comunidad indígena Yakye Axa con Paraguay, párrs. 144-145; sentencia del
} 
piedad indígena deben ser establecidas previamente por ley; ii) sean necesarias; iii) proporcionales; iv) que tengan el fin de lograr un objetivo legítimo en una sociedad democrática; v) previo pago de una justa indemnización. ${ }^{34}$ De esta forma, se da cumplimiento a lo dispuesto en el artículo 21.2 de la $\mathrm{CADH}$, que dispone que «ninguna persona puede ser privada de sus bienes, excepto mediante el pago de una indemnización justa, por razones de utilidad pública o de interés social y en los casos y según las formas establecidas por la ley». Una cuestión relevante es que la Corte IDH ha determinado que las condiciones expropiatorias concurren no solo en caso de total privación de un título de propiedad, sino también en el evento de privación parcial del uso y goce. ${ }^{35}$

Como complemento a lo señalado, se ha establecido que los Estados violan los derechos de los pueblos indígenas a la propiedad cuando otorgan concesiones para la exploración o explotación de recursos naturales, incluidos recursos hídricos, en territorios indígenas que no han sido delimitados, demarcados o titulados, por lo que deben abstenerse de otorgar concesiones mientras no se efectúe una consulta efectiva, se recabe el consentimiento previo libre e informado y se haga la titulación. ${ }^{36}$ En estos casos, el retardo en el proceso de delimitación, demarcación o titulación opera como una agravante de la responsabilidad internacional del Estado, porque la Corte IDH exige que, concurriendo estas circunstancias, el Estado debe recabar el consentimiento, previo libre e informado. ${ }^{37}$

caso Ricardo Canese con Paraguay, Corte Interamericana de Derechos Humanos, fondo, reparaciones y costas, serie C núm. 111, 31 de agosto de 2004, párr. 96; sentencia del caso Herrera Ulloa con Costa Rica, Corte Interamericana de Derechos Humanos, excepciones preliminares, fondo, reparaciones y costas, serie C núm. 107, 2 de julio de 2004, párr. 127; sentencia del caso Ivcher Bronstein con Perú, Corte Interamericana de Derechos Humanos, fondo, reparaciones y costas, serie C núm. 74, 6 de febrero de 2001, párr. 155; sentencia del caso Comunidad indígena Sawhoyamaxa con Paraguay, párr. 137.

34. «Derechos de los pueblos...», párr. 230.

35. «Derechos de los pueblos...», párr. 231. Véase sentencia del caso Pueblo Saramaka con Surinam, párr. 127.

36. «Derechos de los pueblos...», párrs. 187-189. Esta posición está refrendada en los alegatos efectuados por la CIDH en la sentencia del caso Awas Tingni con Nicaragua, Corte Interamericana de Derechos Humanos, fondo, reparaciones y costas, serie C núm. 79, 31 de agosto de 2001, párr. 140(j). También está recogida en una multiplicidad de informes de la CIDH: Informe 40/04, Caso 12.053, Comunidades Indígenas Mayas del Distrito de Toledo (Belice), 12 de octubre de 2004, párr. 153; Informe 40/04, caso 12.053, Comunidades Indígenas Mayas del Distrito de Toledo (Belice), 12 de octubre de 2004, párr. 194. La Organización Internacional del Trabajo, por su parte, se ha pronunciado sobre la consulta en caso de exploración o explotación de minerales u otros recursos naturales que se encuentren en las tierras o territorios indígenas. Asimismo, reconoce el derecho de los pueblos interesados a participar, siempre que sea posible, de los beneficios que reporten tales actividades, y percibir una indemnización equitativa por cualquier daño que puedan sufrir como resultado de tales actividades (Aylwin, Meza-Lopehandía y Yáñez, 2014: 369).

37. La sentencia del caso Pueblo Saramaka con Surinam, párr. 194(a), estableció: «Hasta tanto no se lleve a cabo dicha delimitación, demarcación u otorgamiento de título colectivo respecto del territorio 
La omisión estatal consistente en no tomar las medidas adecuadas ${ }^{38}$ para salvaguardar los derechos indígenas sobre los recursos naturales viola los artículos 1 y 2 de la CADH. ${ }^{39}$ Las acciones positivas suponen la implementación de estándares y regulaciones adecuadas, acorde con los compromisos estatales en el ámbito internacional y a su regulación interna..$^{40}$

\section{Conclusiones}

El análisis normativo y jurisprudencial evidencia notables avances en el reconocimiento de derechos de los pueblos indígenas sobre el entorno, sus territorios y recursos naturales. Es importante resaltar que, de la mano del desarrollo de estándares específicos de derechos ambientales y territoriales a pueblos indígenas, el Sistema Interamericano de Derechos Humanos ha reconocido que el derecho al medio ambiente es un derecho autónomo que implica la protección de la naturaleza en sí misma y los elementos que la componen, independiente de si hay afectación directa a las personas como consecuencia del daño ambiental. También es relevante la relación que se observa en el derecho internacional entre identidad cultural y medio ambiente, que reconoce que la protección de los ecosistemas es fundamental para asegurar las formas de vida tradicionales de los pueblos indígenas, su soberanía alimentaria y su acceso pleno a las fuentes de agua que garantizan la sustentabilidad hídrica de sus territorios. El Sistema, a falta de disposiciones específicas respecto del derecho al medio ambiente sano, el derecho a la alimentación y el derecho al agua de los pueblos indígenas en la Convención, ha recurrido al corpus iuris de los derechos humanos

saramaka, Surinam debe abstenerse de realizar actos que podrían dar lugar a que agentes del propio Estado o terceros, actuando con consentimiento o tolerancia del Estado, puedan afectar la existencia, valor, uso o goce del territorio al cual tienen derecho los integrantes del pueblo saramaka, a menos que el Estado obtenga el consentimiento previo, libre e informado de dicho pueblo».

38. En este punto resulta importante introducir en la discusión el significado de la idea jurídica de igualdad aplicada a la configuración teórica y dogmática de los derechos sociales. Según ella, la igualdad está determinada por un enunciado que está determinado por un contenido mínimo, que verifica la coherencia entre el criterio con arreglo al cual se mide la igualdad y de igual forma la desigualdad, y la finalidad de la medida que introduce la diferenciación, cuya coherencia o razonabilidad implica recurrir a criterios materiales externos al juicio de igualdad. Así concebida, la igualdad remite a un criterio histórico que se expresa en la Constitución que le sirve de marco y, en consecuencia, en el modelo de Estado al que adscribe (Escobar Roca, 2012: 337-362).

39. «Derechos de los pueblos...», párrs. 185, 189.

40. Los mecanismos son múltiples e incluyen el establecimiento de estándares de calidad, producción o emisiones; el licenciamiento o regulación de actividades riesgosas; la sanción penal de actividades dañinas al medio ambiente; instauración de incentivos o desincentivos económicos o regímenes de responsabilidad privada para prevenir daños ambientales o garantizar su compensación, etcétera. «Derechos de los pueblos...», párr. 203. 
aplicables a los pueblos indígenas, conformado por los instrumentos internacionales de derechos humanos citados en este artículo y el artículo 26 de la Convención, para determinar sus alcances normativos por medio de una interpretación evolutiva de las fuentes de derecho internacional, lo que constituye un claro avance jurisprudencial.

\section{Referencias}

Aylwin, José, Matías Meza-Lopehandía y Nancy Yáñez (2013). Los pueblos indígenas y el derecho. Santiago: Lom.

Escobar Roca, Guillermo (2012). Derechos sociales y tutela antidiscriminatoria. Pamplona: Aranzadi Thomson Reuter.

Henderson, Humberto (2011). «La jurisprudencia del Comité de Derechos Humanos sobre los derechos de pueblos indígenas». Ponencia presentada en el seminario Derechos Humanos e Interculturalidad: Hermenéutica y Jurisprudencia Internacional y Nacional. Santiago, 11 y 12 de noviembre de 2011.

O'Donell, Guillermo (2007). Derecho internacional de los derechos humanos: Normativa, jurisprudencia y doctrina de los sistemas universal e interamericano. Santiago: Oficina Regional para América Latina y el Caribe del Alto Comisionado de las Naciones Unidas para los Derechos Humanos.

Steiner, Christian y Marie Christine Fuchs (2019). Convención Americana de Derechos Humanos: Comentario. Bogotá: Konrad-Adenauer-Stiftung. Disponible en https://bit.ly/3gcDMWM.

YÁÑEZ, Nancy (2014). «Nuevos paradigmas para la interpretación jurídica del derecho de aguas en Chile a partir del enfoque de derechos fundamentales y lineamientos para una reforma institucional al modelo chileno de aguas». Tesis para optar al grado de doctor en Derecho, Universidad de Chile.

\section{Sobre la autora}

Nancy Yáñez Fuenzalida es abogada de la Universidad de Chile. Directora del Centro de Derechos Humanos de la Facultad de Derecho de la Universidad de Chile. Máster en Derecho Internacional de los Derechos Humanos, Center for Civil and Human Rights, Universidad de Notre Dame, Estados Unidos. Doctora en Derecho, Universidad de Chile. Especialista en derecho de los pueblos indígenas. Su correo electrónico es nyanez@derecho.uchile.cl. 
El Anuario de Derechos Humanos es una publicación semestral de referencia y consulta en materia de derechos humanos y campos afines. Busca ser un espacio de discusión de los temas centrales en el ámbito nacional e internacional sobre derechos humanos. Es publicado desde 2005 por el Centro de Derechos Humanos de la Facultad de Derecho de la Universidad de Chile.

\author{
EDITORA GENERAL \\ Claudia Iriarte Rivas \\ ciriarter@derecho.uchile.cl \\ EDITORA DE ESTE NÚMERO \\ Liliana Galdámez Zelada \\ lgaldamez@derecho.uchile.cl \\ SITIO WEB \\ anuariocdh.uchile.cl \\ CORREO ELECTRÓNICO \\ anuario-cdh@derecho.uchile.cl \\ LICENCIA DE ESTE ARTÍCULO
}

Creative Commons Atribución Compartir Igual 4.o Internacional

\author{
कै \\ La edición de textos, el diseño editorial \\ y la conversión a formatos electrónicos de este artículo \\ estuvieron a cargo de Tipográfica \\ (www.tipografica.io)
}

